\title{
The Effect on Group Counseling for the Low Self-Concept of Undergraduate
}

\author{
Qinghong Mao \\ School of Psychology, Jiangxi Normal University, Nanchang, China \\ Email:xthn@qq.com
}

How to cite this paper: Mao, Q.H. (2019) The Effect on Group Counseling for the Low Self-Concept of Undergraduate. Open Access Library Journal, 6: e5929. https://doi.org/10.4236/oalib.1105929

Received: November 18, 2019

Accepted: December 9, 2019

Published: December 12, 2019

Copyright $\odot 2019$ by author(s) and Open Access Library Inc.

This work is licensed under the Creative Commons Attribution International License (CC BY 4.0).

http://creativecommons.org/licenses/by/4.0/

(c) (i) Open Access

\begin{abstract}
Objectives: To explore the group counseling on the impact of low self-concept of students. Methods: Filter out 21 students with low levels of self-concept from 80 randomly selected college students, and 11 of them as the experimental group to accept group counseling to explore self-awareness. The group counseling consists of six units and lasts six weeks. Tennessee self-concept scale and interpersonal relationship scale were used for pre- and post-testing before and after counseling; the other 10 college students served as the control group and did not conduct group counseling experiments. A comparative study of the experimental group and control group also compared the pre-test and post-test results of the experimental group. Results: There were significant differences in the results of the experimental group between the pre-test and post-test data; the treated subjects improved the level of self-concept significantly. There was a significant difference between the experimental group and the control group in the post-test. Conclusion: The group counseling to explore self-consciousness can help low levels of self-concept students to understand themselves, be pleased to accept themselves, develop themselves, also enhance their interpersonal skills, environmental adaptability and learning ability can be promoted.
\end{abstract}

\section{Subject Areas}

Education, Psychology

\section{Keywords}

Self-Concept, Interpersonal Relationship, Self-Consciousness, Group Counseling

\section{Introduction}

The history of self-cognition can be traced back to the philosophical era of an- 
cient Greece more than 2000 years ago; however, a more complete explanation of the psychological theory of self was started from W. James's theory of self in 1890 [1] [2]. Since then, self-concept has become one of the hot issues in social psychology and clinical psychology research [3]. Psychologists call people's particular way of thinking about themselves as a "self-concept" [4]. At present, the definition of self-concept is as follows: self-concept is the impression of oneself in the individual's mind, including the understanding of one's existence, personal physical ability, personality, attitude, and thought, etc. It is an organized cognitive structure composed of a series of attitudes, beliefs and values. It connects the various special habits, abilities, ideas, thoughts and emotional organizations, throughout all aspects of experience and behavior [2] [5].

Self-development is an important developing task for adolescents and youth [6] [7]. For college students in the late adolescence and early adulthood, the university stage is the fastest period of their self-concept development, and also a period of more self-concept problems producing [2] [8]. A large number of studies have shown that the development of self-concepts among adolescents and adolescents has a clear positive correlation with their mental health and identity development [9] [10]. Self-concept is the core part of personality. College students' perception of self not only affects their behaviors and also has a close relationship with their personality traits and mental health [3] [11] [12]. A large number of domestic research literature shows that group training has a certain effect on improving students' self-concepts [13] [14] [15].

However, looking at the impact of self-concepts through group counseling in China, it is not difficult to find that there are not many studies specifically targeting individuals with low self-concept levels. This study will use a combination of pre- and post-test design and post-study interviews. The aim is to improve the self-concept level of college students through group psychological counseling so that they can better accept and understand themselves and improve their personality.

\section{Method}

\subsection{Participants}

Utilizing simple random sampling, 80 college students were selected in Jiangxi Normal University, and their interpersonal relationship and self-concept were measured. According to the scores, 21 college students with low self-concept levels were selected to conduct pre- and post-test experiments in the experiment. And they were divided into experimental group and control group: 11 experimental groups, include 4 boys and 7 girls, with an average age of 20 years; another 10 into control groups, include 5 boys and 5 girls, with an average age of 19 years.

\subsection{Questionnaire Measures}

\subsubsection{The Tennessee Self-Concept Scale}

This study used the Tennessee Self-Concept Scale, which was adapted by Yu 
Ziying and revised by Lin Bangjie (1986). The scale consists of 70 questions, ranging from "identical" to "completely different". The whole content includes ten factors, the last one of which is selected from the Minnesota Multiple Personality Test (MMPI) lying scale. So in addition to the tenth factor, the other nine factors are as follows: physiological self, moral self, psychological self, Family self, social self, self-identity, self-satisfaction, self-action, self-scoring, etc. The higher the scores of the first nine factors, the more positive the self-concept, and the higher the self-criticism score, the more negative the self-concept. Lin Bangjie took 143 students from Guozhong Middle School in Taipei as subjects. The retest reliability was between 0.665 and 0.835 , and the half-confidence was between 0.66 and 0.95 [16] [17].

\subsubsection{Interpersonal Relationship Scale}

The scale was compiled by Tu Xiuwen (1999), a Taiwan scholar, concerning Lu Junyue (1981) and revised by Wu Qiongru (1997). The scale consists of 21 questions. Consistency found that the Cronbacha value of each subscale is between 0.6473 and 0.9655 from the original scale, and the Cronbacha value of the full scale is 0.8010 , indicating that the scale has stable reliability. Besides, the three factors extracted from the original scale by factor analysis explained that the total variation was $50.4 \%$, indicating that the construct validity of the questionnaire was acceptable [18].

\subsection{Design}

The study is designed a pre-post test, and the combination of objective measurement and subjective evaluation was adopted. The experimental group received the experimental treatment of self-awareness exploration group psychological counseling for 6 weeks. Every Saturday morning, group counseling activities were conducted in the activity observation room of the Jiangxi Provincial Key Laboratory of Psychology and Cognition Science. The eleven subjects would be interviewed after each activity. The interviews mainly included the participants' understanding of the activities, their feelings and rewards, and their changes after the activities. The interviews' purpose was to evaluate the effect of group counseling for each event. After the last group counseling, the post-test was conducted. The content of the questionnaire was the same as that of the previous test. The other 10 low self-concept scorers were used as the control group and did not do any treatment, but the same questionnaire was taken after the experiment (see Table 1).

\subsection{Group Counseling Program}

The self-awareness exploration group psychological counseling program was designed by the researchers, including 6 thematic units: mutual understanding; know yourself; accept yourself; develop self; communicate with you and me; Take care and say goodbye. The various themes are progressive and interlocking (see Table 2 for details). 
Table 1. Self-awareness exploration group auxiliary experiment design table.

\begin{tabular}{cccc}
\hline Group & Pre-test & Experimental processing & Post-test \\
\hline test group & $\begin{array}{c}\mathrm{o}_{1} \text { (Self-concept and interpersonal } \\
\text { relationship scale) }\end{array}$ & $\mathrm{x}$ (group counseling) & $\mathrm{o}_{2}$ (same as before) \\
Control group & $\begin{array}{c}\mathrm{o}_{3} \text { (Self-concept and interpersonal } \\
\text { relationship scale) }\end{array}$ & - & $\mathrm{o}_{4}$ (same as before) \\
\hline
\end{tabular}

Table 2. List of group auxiliary activities design.

\begin{tabular}{|c|c|c|}
\hline Activity unit & Activity goal & Activities \\
\hline $\begin{array}{l}\text { 1) Mutual } \\
\text { understanding }\end{array}$ & $\begin{array}{l}\text { The members know each other, establish mutual trust, establish } \\
\text { group norms, and stimulate individual interest in others. }\end{array}$ & $\begin{array}{l}\text { Meet the joy, the wind blows, the money, the snowball, } \\
\text { the stick, and the signing of the group. }\end{array}$ \\
\hline 2) know yourself & $\begin{array}{l}\text { Through self-reflection and deep thinking, dialogue with the soul in } \\
\text { a calm atmosphere, looking for the true self. }\end{array}$ & $\begin{array}{l}\text { Big trees and squirrels, "eggs, chickens, people and } \\
\text { gods", who I am, the golden years, the journey of true } \\
\text { self, the favorite of the house, unit feedback }\end{array}$ \\
\hline 3) accept yourself & $\begin{array}{l}\text { After getting a self-assessment after deep reflection and reflection, } \\
\text { combine the other people's objective evaluation of themselves, accept } \\
\text { their strengths and weaknesses, and be willing to accept themselves. }\end{array}$ & $\begin{array}{l}\text { First impression, positive meaning, selling myself-I } \\
\text { am very good, the advantage is bombing, I can be the } \\
\text { ideal, Unit feedback (self-esteem scale) }\end{array}$ \\
\hline 4) Develop yourself & $\begin{array}{l}\text { After accepting the shortcomings, it is important to reduce or avoid } \\
\text { the bad influences and consequences brought by the shortcomings, } \\
\text { experience to fully face its shortcomings and dare to challenge it, } \\
\text { and conquer it finally, develop and perfect its personality. }\end{array}$ & $\begin{array}{l}\text { Grab the stool, learn to bravely say "no", "who said that } \\
\text { I can't!", Mystery message box, unit feedback (personal } \\
\text { evaluation questionnaire) }\end{array}$ \\
\hline $\begin{array}{l}\text { 5) communicate } \\
\text { with you and me }\end{array}$ & $\begin{array}{l}\text { I met myself, accepted myself, and developed my task afterward to } \\
\text { have a good interpersonal relationship. Learn to put yourself in a } \\
\text { group and get to know yourself in the group. }\end{array}$ & $\begin{array}{l}\text { Fighting ahead, rear support, blindness, } \\
\text { communication without limits, trust fall, unit feedback } \\
\text { (interpersonal trust scale) }\end{array}$ \\
\hline $\begin{array}{l}\text { 6) Take care } \\
\text { and say goodbye }\end{array}$ & $\begin{array}{l}\text { Looking back at the experience and experience of the previous five } \\
\text { activities, by giving back to each other, knowing their growth and } \\
\text { change in the group, and bidding farewell to each other. }\end{array}$ & $\begin{array}{l}\text { Team rhythm, music relaxation, filling out questionnaires } \\
\text { (group satisfaction self-rating and post-testing), dating } \\
\text { family, cherish, goodbye (main interview) }\end{array}$ \\
\hline
\end{tabular}

\section{Results}

\subsection{Experimental Group Self-Concept and Interpersonal Relationship Results}

According to the statistical analysis method of the pre-test data of the quasi-experimental design, the experiment uses spss 18.0 to analyze the data and obtain the following results:

Combined with Table 3 and Table 4, it can be seen that before the experimental treatment, that is, before the group psychological counseling, there was only a low correlation between the self-concept and the interpersonal relationship scores of the experimental group, and the difference was not significant. But after the treatment, the self-concept of the experimental group was significantly improved and showed extremely significant differences $(t=-3.411, p<0.01)$; the interpersonal relationship score was also significantly improved, and the difference was significant $(t=-0.72, p<0.05)$.

\subsection{Control Group Self-Concept and Interpersonal Relationship Results}

It can be seen from Table 5 that over time, the self-concept and interpersonal 
Table 3. Experimental group self-concept and interpersonal relationship pre-test correlation.

\begin{tabular}{ccc}
\hline & & $\begin{array}{c}\text { Experimental group interpersonal } \\
\text { relationship total score }\end{array}$ \\
\hline self-concept total score & Pearson correlation & 0.343 \\
& Significant (bilateral) & 0.302 \\
$\mathrm{~N}$ & 11 \\
\hline
\end{tabular}

Table 4. Analysis of the differences between the self-concept and interpersonal relationship in the experimental group.

\begin{tabular}{cccccc}
\hline & & Mean & Standard deviation & $\mathrm{t}$ & sig \\
\hline \multirow{2}{*}{ self-concept total score } & Pre-test & 65.36 & 4.52 & -3.41 & 0.007 \\
& Post-test & 80.45 & 15.14 & & \\
interpersonal relationship & Pre-test & 49.18 & 3.37 & -0.72 & 0.049 \\
\hline
\end{tabular}

Table 5. Analysis of differences between self-concept and interpersonal relationship in the control group.

\begin{tabular}{cccccc}
\hline & & Mean & Standard deviation & $\mathrm{t}$ & sig \\
\hline \multirow{2}{*}{ self-concept total score } & Pre-test & 64.90 & 5.20 & & \\
& Post-test & 66.45 & 4.89 & -1.33 & 0.21 \\
& Pre-test & 49.54 & 3.30 & & \\
interpersonal relationship & Post-test & 49.81 & 3.00 & -0.71 & 0.49 \\
& & & & \\
\hline
\end{tabular}

relationship scores of the control group did not change significantly in the pre-test, and they were stable throughout the experiment.

\subsection{Pre-Test Results of Self-Concept and Interpersonal Relationship between Experimental Group and Control Group}

The statistical test between the experimental group and the control group was carried out. In terms of self-concept, it was found that the score of the experimental group was much larger than the control group, and the difference was extremely significant $(t=2.96, P<0.01)$. In terms of interpersonal relationships, the experimental group scores were significantly higher than the control group $(\mathrm{t}$ $=0.29, \mathrm{P}<0.05)$, as shown in Table 6 .

\section{Analysis and Discussion}

The results of this study indicated that, in the longitudinal comparison, the self-concept and interpersonal relationship scores of the experimental group were significantly improved after self-awareness group psychology counseling; while the control group did not receive the experimental treatment of group psychological counseling, in its own right, also after the same time as the experimental 
Table 6. Results of differences in self-concept and interpersonal relationship between the two groups.

\begin{tabular}{cccccc}
\hline & & Mean & Standard deviation & t & sig \\
\hline $\begin{array}{c}\text { Self-concept post-test and } \\
\text { pre-measurement difference }\end{array}$ & test group & 15.09 & 14.67 & & \\
Control group & 1.54 & 3.86 & 2.96 & 0.002 \\
$\begin{array}{c}\text { Interpersonal relationship post-test } \\
\text { and pre-measurement difference }\end{array}$ & test group & 0.55 & 2.91 & 0.29 & 0.044 \\
\hline
\end{tabular}

group, the self-concept and interpersonal relationship did not improve well; from the horizontal comparison, the self-concept and interpersonal relationship between the experimental group and the control group were significantly different. Among the qualitative materials obtained from the interviews, the following are taken from some of the recording materials: "Before attending, I am not confident enough about myself. I don't know how to deal with some problems in interpersonal relationships, and I am embarrassed to reject others' excessive requests. I don't know how to accept myself, I will exaggerate my shortcomings, etc. After I participated, I first enjoyed my mind and body, learned a lot of psychological games, deepened my understanding of psychology, and learned to euphemistically reject others' irrationality request. I start to become self-confident, try to handle the embarrassing problems in interpersonal relationships, know a lot of new students to get friendships, and I am very happy to join the group.", "I feel very relaxed during the event". "A good friend around me said that I became cheerful after I joined the group". "I have always been confused about what to do next, or what I should do, what I am doing, always thinking about the environment and others influencing on myself, but I have never thought of all the problems from myself. After participating in the group, I got to know myself deeply in 'Who am I?', 'selling myself-I am very good', 'Benefit bombing', 'I can become ideal, I've found confidence in it."' It is worthy of recognition that the group activities have brought me a lot of happiness. During this period, I have met many people who are worthy of contact. In the mutual exchanges, I have learned some new truths, gained a lot of life sentiments, and improved many of my ideas, in short, benefiting a lot. This indicates that the self-awareness exploration group psychological counseling which designed six-unit played its due role.

The results of this study show that through group counseling, psychological activities can help improve the interpersonal relationship of college students and enhance their level of self-concept. In the early days of group counseling, these low self-concept scorers were more cautious and limited their behavior. However, as the activities deepened, their willingness to participate in the activities was stronger and more relaxed. By participating in the event, they improved their self-awareness and made them score higher in the post-test.

In short, the conclusions of this study indicate that the self-awareness exploration group is effective in improving the level of self-awareness of students. It can 
help low-concept students to recognize themselves, accept themselves, develop themselves, and improved their interpersonal ability, environmental adaptability, and learning ability. In addition, compared with the "one-on-one" psychological counseling interview, the implementation of group counseling is more cost-effective for improving the mental health of college students, which is conducive to alleviating the contradiction between the shortage of teachers in mental health education in colleges or universities and the sharp increase in the number of students after the expansion of enrollment. Also, the self-awareness exploration group can prevent low self-concept students from developing into psychological barriers. This study proves that mental health education should focus on the form of group counseling.

\section{Funding}

This study was supported by the research project of key research base of humanities and social sciences in universities in Jiangxi province [JD16115].

\section{Conflicts of Interest}

The author declares no conflicts of interest regarding the publication of this paper.

\section{References}

[1] Li, G.Z. (2012) James “Self” Theory Research. Jilin University, Changchun.

[2] Ling, H., Xia, Y., Zhang, J.R., et al. (2016) Structure and Development of Self-Concept. Chinese Journal of Clinical Psychology, 24, 150+176-180.

[3] Chen, C., Liu, T.Q., Chen, J. and Zheng, M.J. (2010) Analysis of the Effect of Self-Concept on Stress Life Events and Depression and Anxiety. International Journal of Psychiatry, 37, 193-196.

[4] Brown, J. (2004) Self. (Translated by Chen, H.Q.). People's Posts and Telecommunications Press, Beijing.

[5] Yu, L., Song, W.T. and Pan, F. (2005) Progress in the Development of Children's Self-Concept and Its Influencing Factors. Chinese Journal of Behavioral Medicine and Brain Science, 14, 278-280.

[6] Arnett, J.J. (2015) Emerging Adulthood: The Winding Road from the Late Teens through the Twenties. 2nd Edition, Oxford University Press, New York. https://doi.org/10.1093/oxfordhb/9780199795574.013.9

[7] Erikson, E.H. (1963) Childhood and Society. 2nd Edition, Norton, New York.

[8] Yao, X. (2003) Research on the Development of Self-Concept of College Students. Chinese Journal of Mental Health, No. 1, 42-44.

[9] Kawamoto, T. (2020) The Moderating Role of Attachment Style on the Relationship between Self-Concept Clarity and Self-Esteem. Personality and Individual Differences, 152, Article ID: 109604. https://doi.org/10.1016/j.paid.2019.109604

[10] Suszek, H., Fronczyk, K., Kopera, M. and Maliszewski, N. (2018) Implicit and Explicit Self-Concept Clarity and Psychological Adjustment. Personality and Individual Differences, 123, 253-256. https://doi.org/10.1016/j.paid.2017.11.038

[11] Zhang, L. and Xu, Q. (2007) Effects of Self-Concept, Individual Self-Esteem and 
Collective Self-Esteem on Subjective Well-Being of College Students. Chinese Journal of Clinical Psychology, 15, 609-611.

[12] Kong, X.J. (2006) Research on the Relationship between Self-Concept and Defense Style of College Students. Chinese Journal of Clinical Psychology, 14, 61-62+60.

[13] Wang, H.Z. and Gao, H.Y. (2009) Research on the Impact of Experiential Team Development Training on College Students' Self-Concept. Zhejiang Sports Science, 31, 97-100.

[14] Wang, H.R. (2010) Research on the Effect of Interpersonal Group Training on Improving College Students' Self-Concept. Chinese Journal of Health Psychology, No. 2, 68-69.

[15] Xia, W., Mu, W., Luo, B. and Ding, J. (2010) Experimental Research on the Influence of Outward Training on College Students' Self-Concept. Journal of Military Sports, No. 1, 95-97.

[16] Wang, X.D. and Wang, M.H. (1999) Handbook of Mental Health Rating Scale (Updated Version). Chinese Journal of Mental Health, 342-343.

[17] Lin, S.X. (2003) Experimental Study on the Influence of Different Orientations of Life Education on Self-Concept, Interpersonal Relationship and Life Meaning of Middle School Students. Institute of Death Studies, South China University, Nanhua University, Chiayi County, Taiwan, China.

[18] Liu, X.W. (2003) Research on the Influence of Different Orientation Life Education Courses on Self-Concept, Interpersonal Relationship and Life Meaning of High School Students. Institute of Death Studies, South China University, Nanhua University, Chiayi County, Taiwan, China. 